\title{
Circuitous embolic hemorrhagic stroke: carotid pseudoaneurysm to fetal posterior cerebral artery conduit: a case report Romy Hoque ${ }^{1}$, Eduardo Gonzalez-Toledo ${ }^{1,2}$, Alireza Minagar*1 and Roger E Kelley ${ }^{1}$
}

\author{
Address: ${ }^{1}$ Department of Neurology, Louisiana State University Health Sciences Center, Shreveport, LA 71104, USA and ${ }^{2}$ Department of Radiology, \\ Louisiana State University Health Sciences Center, Shreveport, LA 71104, USA \\ Email: Romy Hoque - rhoque@lsuhsc.edu; Eduardo Gonzalez-Toledo - egonz1@lsuhsc.edu; Alireza Minagar* - aminag@lsuhsc.edu; \\ Roger E Kelley - rkelly@lsuhsc.edu \\ * Corresponding author
}

Published: 25 February 2008

Journal of Medical Case Reports 2008, 2:6I doi:I0.1186/I752-1947-2-6I
Received: 25 October 2007

Accepted: 25 February 2008

This article is available from: http://www.jmedicalcasereports.com/content/2/I/6I

(C) 2008 Hoque et al; licensee BioMed Central Ltd.

This is an Open Access article distributed under the terms of the Creative Commons Attribution License (http://creativecommons.org/licenses/by/2.0),

which permits unrestricted use, distribution, and reproduction in any medium, provided the original work is properly cited.

\begin{abstract}
Introduction: The cervical internal carotid artery (ICA) is susceptible to injury through various mechanisms, including dissection, which can lead to pseudoaneurysm formation. Pathological processes affecting the ICA, in association with an ipsilateral fetal posterior cerebral artery (PCA), resulting in parieto-occipital strokes are rarely reported.

Case Presentation: We present a patient with a left PCA territory, presumably embolic, stroke with early hemorrhagic transformation. The identified nidus of the embolus was a carotid artery pseudoaneurysm. Manifestations included right homonymous hemianopsia with right hemiparesis and hemisensory loss.

Conclusion: Our case is unique, and of clinical interest, because it illustrates both the potential anterior-posterior circulation conduit provided by a fetal origin PCA as well as the apparent early hemorrhagic transformation of embolic infarcts that can lead to further confusion from a mechanistic standpoint.
\end{abstract}

\section{Introduction}

Unexplained hemorrhagic stroke is not infrequently encountered. There are a number of possible mechanisms for such a presentation and it is important to determine the pathogenesis as accurately as possible in an effort to prevent recurrence. Vascular dissection represents tearing of the vessel between the adventia and the intima or the intima and the media. Clinical presentation is usually related to hematoma formation which can compromise the vessel lumen and lead to cerebral infarction as the most common clinical presentation [1]. An alternative mechanism of stroke is aneurysmal outpouching of the affected vessel, resulting in what is termed a pseudoaneurysm, and this can be associated with thrombus formation with the potential for thrombo-embolism into the more distal circulation [2]. Fibromuscular dysplasia (FMD) can contribute to predisposition to vascular dissection $[3,4]$.

Internal carotid artery (ICA) thrombo-embolic disease can be impacted by the presence of a fetal origin ipsilateral posterior cerebral artery [5]. There have been infrequently reported cases of posterior circulation stroke attributed to such a potential conduit [6-9]. We report a patient with a left parieto-occipital hemorrhage in the setting of a left 
ICA pseudoaneurysm and ipsilateral fetal origin posterior cerebral artery (PCA).

\section{Case Presentation}

A 51 year old right-handed male presented with acute right sided weakness and right homonymous hemianopsia. He reported a recent upper respiratory tract infection with violent cough. Past medical history was pertinent for hypertension and hyperlipidemia treated over the past five to six years with a statin drug and a calcium channel blocking agent. He also recalled a stunning blow to his head, without loss of consciousness, twelve years prior to presentation. His general physical examination was unremarkable. He was afebrile, in normal sinus rhythm and had no ocular or cervical bruit. Neurological examination revealed a dense right homonymous hemianopsia, with a right sided weakness, affecting the face, arm and leg with $4 / 5$ strength, and right hemisensory loss.

Computerized tomography (CT) and magnetic resonance imaging (MRI) of the head one day later revealed an evolving left parieto-occipital primary hemorrhage versus hemorrhagic infarction (Figure 1A-I). Carotid angiogram revealed a left ICA pseudoaneurysm (Figure 1J) in association with a left fetal PCA (Figure 1L). There was some evidence of fibromuscular dysplasia (FMD) and it was felt that his pseudoaneurysm formation was related to this in association with an apparent ICA dissection. He underwent stenting of the left ICA, with coiling of the pseudoaneurysm, one month after presentation (Figure $1 \mathrm{~K}$ ).

He was treated with clopidogrel, $75 \mathrm{mg}$ a day, for six months after his interventional procedure, and has then been maintained on aspirin $81 \mathrm{mg}$ per day for the past two years of observation with essentially full recovery of motor and sensory function on the right side, other than mildly impaired dexterity, but with persistent dense right homonymous hemianopsia.

\section{Discussion}

Roughly $10 \%$ to $32 \%$ of the population has a fetal origin PCA supplying their parieto-occipital lobes in which the P1 segment is hypoplastic and the PCA is supplied primarily by a larger diameter homolateral posterior communicating artery $[5,10]$. Other potentially persistent primitive carotid basilar anastomoses include the primitive trigeminal artery, the primitive acoustic (otic) artery, the primitive hypoglossal artery, and the primitive proatlantic artery. The fetal origin PCA anatomic variant provides a potential conduit for emboli from ipsilateral ICA disease [6-9]. To the best of our knowledge, artery-to-artery embolism from cervical ICA pseudoaneurysm to fetal PCA has not been previously reported. Pseudoaneurysm usually develops as a result of trauma, with rupture of the affected artery through the intima and media into the subadventi-

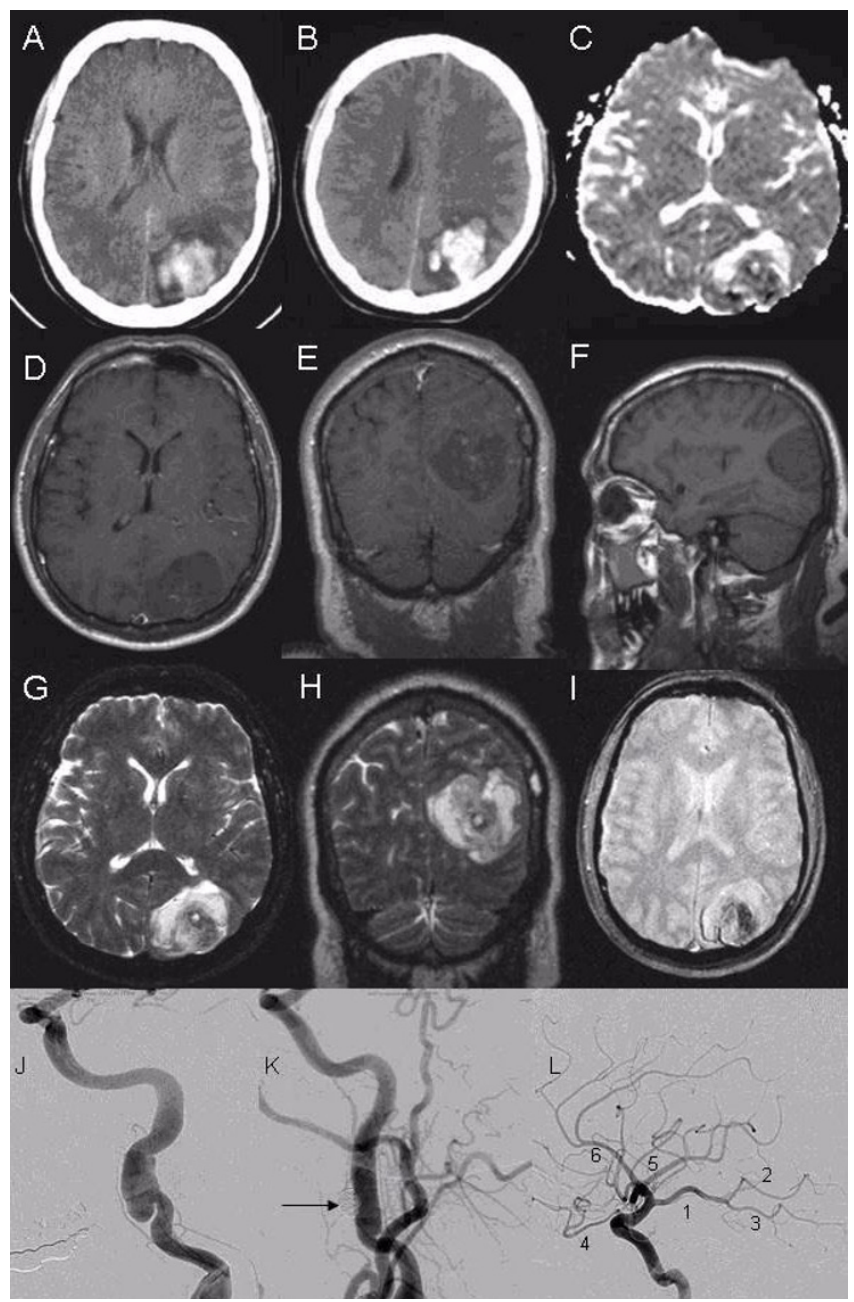

Figure I

Neuroimaging of patient with occipital hemorrhage secondary to carotid dissection. A-B: Computerized tomography (CT) of the head showing left occipital hemorrhage. C: Diffusion weighted imaging (DWI). D, E, F: Axial, coronal, and sagital $\mathrm{TI}$-weighted magnetic resonance imaging (MRI). G, H: Axial and coronal T2-weighted MRI. I: Gradient echo. J, K, L: Angiogram of left carotid artery. J: Left carotid angiogram showing pseudoaneurysm. K: Left carotid angiogram after deployment of coil (arrow) into pseudoaneurysm. L: Left internal carotid artery (ICA) angiogram with branches. I: Fetal origin posterior cerebral artery (PCA) from ICA. 2-3: Anterior and posterior branches of PCA, respectively. 4: Ophthalmic artery. 5: Middle cerebral artery. 6: Anterior cerebral artery.

tial plane. The resulting tear is contained by the adventitia forming a pseudoaneurysm. Unlike true aneurysms, pseudoaneurysms do not involve dilatation of the entire vessel wall. 
FMD is not only associated with predisposition for initial cervical artery dissection, but also with risk of recurrence [11]. In a study of carotid artery aneurysms [12], 5.5\% were attributed to FMD and $6.6 \%$ were attributed to trauma. There is not only the potential for ischemic stroke, but also for intracranial hemorrhage as a complication of FMD [13].

Our patient initially presented both with features mimicking an MCA stroke (hemiplegia and hemisensory loss); along with the features typical of PCA stroke (bilateral visual field defects). Our patient's neuroimaging demonstrates an occipital cortical stroke extending to the posterior parietal lobe and sparing the mesencephalon and posterolateral thalamus. The P3 and P4 segment of the PCA (superficial PCA) supply this territory. Previous studies have shown that $17 \%$ of patients with pure cortical PCA strokes have face-arm-leg motor deficits, and 23\% have sensory deficits in the same distribution [14]. These studies have demonstrated that embolism is the predominant cause of superficial PCA infarction, as presumably occurred in our case.

Early spontaneous hemorrhagic transformation of an underlying embolic ischemic infarction was the suspected pathophysiological mechanism in our patient given the presence of the left ICA pseudoaneurysm as a potential source of emboli. Early hemorrhagic transformation of cerebral infarcts has been linked to embolism, especially from the heart [15]. Artery to artery embolism from ICA pseudoaneurysm to fetal PCA resulting in parieto-occipital ischemia with early hemorrhagic transformation has not been previously reported.

\section{Conclusion}

Our case is unique, and of clinical interest, because it illustrates both the potential anterior-posterior circulation conduit provided by a fetal origin PCA as well as the apparent early hemorrhagic transformation of embolic infarcts that can lead to further confusion from a mechanistic standpoint. Recognition of this anatomic variant can lead to important angiographic diagnostic testing and possibly interventional therapy with newer endovascular stenting techniques.

\section{Competing interests}

The author(s) declare that they have no competing interests.

\section{Authors' contributions}

All authors contributed to each stage of this work. This means that RH, EGT, AM, and REK all have: (1) made substantial contributions to conception and design, or acquisition of data, or analysis and interpretation of data; (2) been involved in drafting the manuscript or revising it crit- ically for important intellectual content; and (3) given final approval of the version to be published.

\section{Acknowledgements}

The patient gave written informed consent for publication of this report.

\section{References}

I. Hart RG, Easton DF: Dissections of cervical and cerebral arteries. Neurol Clin North Am 1983, I(I): I55-I83.

2. Schievink WI: Spontaneous dissection of the carotid and vertebral arteries. N EnglJ Med 200I, 344:898-906.

3. Benedict WJ, Prabju V, Viola M, Biller J: Carotid artery pseudoaneurysm resulting from an injury to the neck by a fouled baseball. I Neurol Sci 2007, 256:94-99.

4. Steiger HJ, Turowski B: Fibromuscular dysplasia. N Engl J Med 2004, 350: 1862-187I.

5. Battacharji SK, Hutchinson EC, McCall AJ: The Circle of Willis the incidence of development abnormalities in normal and infarcted brains. Brain 1967, 90:747-758.

6. Alexander Y, Poppe JM, Glikstein R, Leventhal M: Fibromuscular dysplasia with carotid artery dissection presenting as an isolated hemianopsia. J Stroke Cerebrovas Dis 2007, 16(3):130-134.

7. Kuker W, Mull M, Block F, Thron A: Carotid artery dissections presenting as isolated posterior cerebral artery infarctions. J Neurol 1997, 244:324-327.

8. Bourcier-Bareil F, Hommet C, Cottier JP, Arsene S, Rossazza C: Hemianopsia related to dissection of the internal carotid artery. I Neuroophthalmol 1999, 19:136-139.

9. Pessin MS, Kwan ES, Scott RM, Hedges TR: Occipital infarction with hemianopsia from carotid occlusive disease. Stroke 1989 , 20:409-4II.

10. Van Overbeeke JJ, Hillen B, Tulleken CA: A comparitive study of the circle of Willis in fetal and adult life. The configuration of the posterior bifurcation of the posterior communicating artery. J Anat 1991, 176:45-54.

II. de Bray JM, Marc G, Pautot V, Vielle B, Pasco A, Lhoste P, Dubas F: Fibromuscular dysplasia may herald symptomatic recurrence of cervical artery dissection. Cerebrovasc Dis 2007, 23:448-452.

12. Radak D, Davidovic L, Vukobratov V, llijevski N, Kostić D, Maksimović Z, Vucurević G, Cvetkovic S, Avramov S: Carotid artery aneurysms: Serbian multicentric study. Ann Vasc Surg 2007, 21:23-29.

13. Allen CA, Ely KA: A 44-year old woman with intracranial hemorrhage. Arch Pathol Lab Med 2005, I 29: 169-170.

14. Kumral E, Bayulkem G, Atac C, Alper Y: Spectrum of superficial posterior cerebral artery territory infarcts. Eur J Neurol 2004, I I:237-246.

15. Bogousslavsky J, Reegli F, Uske A, Maeder P: Early spontaneous hematoma in cerebral infarct: is primary cerebral hemorrhage overdiagnosed? Neurology 1991, 41:837-840.

Publish with Bio Med Central and every scientist can read your work free of charge

"BioMed Central will be the most significant development for disseminating the results of biomedical research in our lifetime. "

Sir Paul Nurse, Cancer Research UK

Your research papers will be:

- available free of charge to the entire biomedical community

- peer reviewed and published immediately upon acceptance

- cited in PubMed and archived on PubMed Central

- yours - you keep the copyright 